\title{
Early Compositional Changes during Postharvest Senescence of Broccoli
}

\author{
Graeme A. King \\ New Zealand Institute for Crop and Food Research Ltd., Levin, New Zealand \\ Stephen C. Morris ${ }^{1}$ \\ Commonwealth Scientific and Industrial Research Organisation, Division of Horticulture, Sydney, \\ Australia
}

Additional index words. Brassica oleracea var. italica, respiration, ethylene, color, sugar, starch, organic acids, protein, amino acid, ammonia

\begin{abstract}
Compositional changes during the postharvest senescence of broccoli branchlets held at 20C in the dark were investigated, particularly during the first 24 hours. Major losses of sugars, organic acids, and proteins from floral, middle, and base sections of branchlets were detected during the first 6 hours. Between 12 and 96 hours, free amino acid pools increased (especially the amides glutamine and asparagine) for all sections of branchlets, while ammonia accumulated only in floral sections. Results are discussed in relation to the nature of the processes that set the tissues on the pathways leading to postharvest senescence.
\end{abstract}

Studies of postharvest senescence in horticultural crops have usually concentrated on mature tissue (e.g., fruit pericarp tissue) in which changes occur relatively slowly. In contrast, organs containing immature tissue that is actively growing at harvest (e.g., asparagus and broccoli) senesce rapidly. Major physiological, biochemical, and molecular changes have been demonstrated within $3 \mathrm{~h}$ after harvesting asparagus spears (Davies and King, 1993; Hurst et al., 1993b; King et al., 1990; Lill et al., 1990). Since all crops initially spend a period at ambient temperature after harvest (while the crop is graded and packed), and then frequently during display and sale, an understanding of early changes following harvest is essential for accurate interpretation of subsequent changes, which may include storage at other temperatures.

Fresh broccoli is highly perishable with a storage life of 3 to 4 weeks in air at 0C (Makhlouf et al., 1989; Smith, 1940) and 2 to 3 days in air at 20C (Wang, 1977). As broccoli deteriorates, the head yellows due to degradation of chlorophyll (Wang, 1977). Decay is common on florets during advanced stages of senescence (Aharoni et al., 1985).

Ethylene plays an important role in regulating the yellowing of broccoli florets. Application of exogenous ethylene or propylene hastens yellowing (Aharoni et al., 1985; Tian et al., 1994). Conversely, application of anti-ethylene agents (aminoethoxyvinylglycine, $\mathrm{CO}_{2}$, silver ions, rhizobitoxine, sodium benzoate, benzyladenine, and gibberellic acid) retards yellowing (Aharoni et al., 1985; Wang, 1977). The sensitivity of broccoli florets to exogenous propylene may also increase after harvest (Tian et al., 1993). However, the relationship between ethylene and other physiological changes during postharvest senescence of broccoli has not been characterized.

We have previously described physiological changes occurring early after harvest of broccoli, including decreased $\mathrm{CO}_{2}$ production and a reduced respiratory quotient (RQ) (King and Morris, 1994). In this paper, we detail compositional changes during the senescence of broccoli held at 20C in the dark for up to $96 \mathrm{~h}$, particularly those changes occurring during the first $24 \mathrm{~h}$. Branchlets

Received for publication 20 Sept. 1993. Accepted for publication 11 Feb. 1994. The cost of publishing this paper was defrayed in part by the payment of page charges. Under postal regulations, this paper therefore must be hereby marked advertisement solely to indicate this fact.

${ }^{1}$ To whom reprint requests should be addressed. were used as they are a useful model system for investigating changes during senescence of broccoli (King and Morris, 1993).

\section{Materials and Methods}

Plant material and holding conditions. 'Green Belt' broccoli (Brassica oleracea L. var. italica) heads were harvested at maturity from a commercial field at dawn, stripped of remaining leaves, and transported to the laboratory within $1.5 \mathrm{~h}$ of harvest. Heads were surface-sterilized with $100 \mathrm{ppm}$ sodium hypochlorite (Rushing, 1990).

Three branchlets ( $\approx 40 \mathrm{~g}$ each; Fig. 1) were excised from each head using a sterile scalpel. The branchlets were obtained from the second layer above the head base. These were considered to represent branchlets of an average size and developmental age on the head. Branchlets were placed in sterilized glass jars (550-ml capacity) and held at 20C in the dark, except for brief periods of light when measurements were being taken. The containers were aerated continuously with humidified, ethylene-free air at a flow rate of $\approx 1.5$ liters $\cdot \mathrm{h}^{-1}$. Containers were equilibrated for $1 \mathrm{~h}$ before initial measurements.

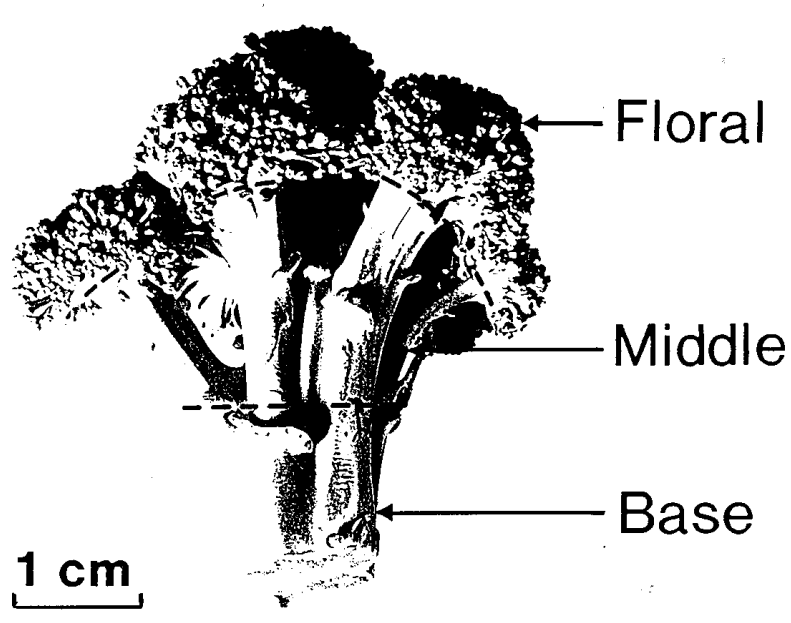

Fig. 1. Sections of broccoli branchlets used for compositional analyses. At each sampling, branchlets were divided into three sections: floral, middle, and base. 
Respiration, ethylene production, and color measurements. Carbon dioxide production and $\mathrm{O}_{2}$ consumption were measured by infrared gas analysis (PIR-2000; Horiba, Tokyo) and paramagnetic oxygen analysis (Servomex Series 1100; Servomex, Sussex, U.K.) of the outflowing airstream from the glass jars. Ethylene production was measured by injecting 1-ml samples of the outflowing airstream into a gas chromatograph (Loenco, Altadera, Calif.) fitted with a flame-ionization detector (King and Morris, 1993).

Color of florets was measured non-destructively by reflectance using a chromameter (model II; Minolta, Osaka, Japan) with an 8mm measuring head and D-65 (6504K) illuminant. Reflectance was measured on florets at three equally spaced sites around the circumference of each branchlet. These experiments were replicated five times.

Sample preparation for compositional analyses. A separate batch of branchlets obtained from heads harvested at the same time as those for the physiological studies was used for compositional analyses. At each sampling time, branchlets were cut into three tissue sections (floral, middle, and base; Fig. 1), immediately frozen in liquid $\mathrm{N}$, stored at $-20 \mathrm{C}$, and later freeze-dried and pulverized. All assays were performed on duplicate or triplicate samples of the pulverized material. These experiments were replicated three times, with the three branchlets comprising each replicate being obtained from a single head.

Soluble sugar determination. Freeze-dried material $(20 \mathrm{mg})$ was extracted with $0.5 \mathrm{ml} 80 \%$ (v/v) aqueous methanol at $60 \mathrm{C}$ for 15 min (Wade and Morris, 1982). After brief centrifugation $(15,000 \times g, 5 \mathrm{~min}), 75$ to $150 \mu \mathrm{l}$ of the supernatant were analyzed for soluble sugars using high-performance liquid chromatography (HPLC). Chromatographic conditions were as described by Wade and Morris (1982), using a Waters (Mass.) Si RadialPak modified with tetraethylenepentamine (TEPA). The mobile phase was $80 \%$ (v/v) aqueous acetonitrile containing $0.1 \%$ TEPA run to waste.

Starch determination. Soluble sugars were removed from 20 $\mathrm{mg}$ freeze-dried material by adding $1 \mathrm{ml} 80 \%$ (v/v) aqueous methanol, vortexing briefly, and centrifuging at $15,000 \times g$ for 20 min. The supernatant was discarded and the pellet re-extracted twice more as above.

Starch was solubilized by resuspending the pellet in $0.5 \mathrm{ml} 8 \mathrm{M}$ $\mathrm{HCl}$, adding $2 \mathrm{ml}$ dimethylsulfoxide (DMSO), and incubating the samples in a closed flask for $1 \mathrm{~h}$ at 60C with gentle shaking. Samples were quickly cooled to room temperature on ice, and 0.5 $\mathrm{ml} 8 \mathrm{M} \mathrm{NaOH}$ were added. The solution was made up to $10 \mathrm{ml}$ with 0.112 M sodium citrate $(\mathrm{pH} 4.0)$. Samples were clarified by centrifugation $(15,000 \times g, 5 \mathrm{~min})$. Aliquots $(200 \mu \mathrm{l})$ of the supernatant were assayed in duplicate for starch using an ultraviolet (UV) starch test kit (Boehringer, Mannheim, Germany) as described in the product literature, except that the final assay volume was $1.16 \mathrm{ml}$. Recoveries of standard starch ranged from $87 \%$ to $94 \%(n=3)$. Data were not corrected for recovery difference.

To confirm that the HCl-DMSO extraction had successfully solubilized the starch present in the tissue sections, the pellets remaining after solubilization were stained with iodine-potassium iodide (O'Brien and McCully, 1981) and examined by microscopy.

Organic acid determination. Organic acids were extracted from $20 \mathrm{mg}$ freeze-dried material with $500 \mu 10.1 \%$ orthophosphoric acid at $95 \mathrm{C}$ for $20 \mathrm{~min}$. The tubes were then centrifuged $(15,000 \times g, 10 \mathrm{~min})$. The pellet was re-extracted as above, and the supernatants combined and made up to $1 \mathrm{ml}$. A $20-\mu \mathrm{l}$ aliquot was injected onto a $4-\mu \mathrm{m}$ radial compression column (C18 Novapak, Waters) running on a HPLC system (Series 6000, Waters). Solvent was $0.1 \%$ orthophosphoric acid with a flow rate of $1 \mathrm{ml} \cdot \mathrm{min}^{-1}$ and $\mathrm{UV}$ detection at $230 \mathrm{~nm}$.

Quantitative protein analysis. Total protein was solubilized by resuspending $20 \mathrm{mg}$ freeze-dried tissue in $1.5 \mathrm{ml} 0.1 \mathrm{M} \mathrm{NaOH}$ containing $1 \%(\mathrm{w} / \mathrm{v})$ sodium dodecyl sulfate (SDS) and heating in a boiling water bath for $10 \mathrm{~min}$. Cell debris was pelleted by centrifugation $(15,000 \times g, 10 \mathrm{~min})$ and the pellet was re-extracted as above. Samples $(500 \mu \mathrm{l})$ of the pooled supernatants were diluted to $1 \mathrm{ml}$ with distilled water. Protein was precipitated by adding 25 $\mu \mathrm{l}$ soluble yeast RNA ( $5 \mathrm{mg} \cdot \mathrm{ml}^{-1}$; Sigma) and $200 \mu \mathrm{l} 100 \%(\mathrm{w} / \mathrm{v})$ trichloroacetic acid. Samples were left on ice for $1 \mathrm{~h}$. After centrifugation $(15,000 \times g, 20 \mathrm{~min}, 4 \mathrm{C})$, the pellet was resuspended in $0.1 \mathrm{~m} \mathrm{NaOH}$ containing $1 \%$ (w/v) SDS. Protein was estimated in triplicate for each sample using the method of Lowry et al. (1951), with bovine serum albumen in $0.1 \mathrm{M} \mathrm{NaOH}$ containing $1 \%$ (w/v) SDS as standard.

Amino acid and ammonia determinations. Freeze-dried material $(20 \mathrm{mg})$ was extracted with $1 \mathrm{ml} 80$ ethanol : 20 water (v/v) at room temperature for 15 min while being gently shaken. After centrifugation $(15,000 \times g, 5 \mathrm{~min})$, a $25-\mu$ l aliquot was removed and dried under vacuum. This was then derivatized with phenylisothiocyanate to produce phenylisothiocarbamyl amino acids. A 10-liter aliquot was injected onto a column (C18 PicoTag, Waters) held at 38C (PicoTag HPLC System, Waters). The mobile phase consisted of a two-solvent gradient. Buffer A was $150 \mathrm{~mm}$ sodium acetate at $\mathrm{pH} 6.4$, and buffer $\mathrm{B}$ was 60 acetonitrile : 40 water (v/v). The mobile phase was run with a gradient from $0 \%$ to $46 \%$ Buffer A over $10 \mathrm{~min}$, then $100 \%$ Buffer B for 2 min. Ultraviolet detection was at a wavelength of $254 \mathrm{~nm}$. Ammonia was analyzed by the alkaline hypochlorite/phenol nitroprusside reaction (King et al., 1990).

\section{Results}

Respiration, ethylene production, and color changes. Carbon dioxide was initially produced rapidly from branchlets $(\approx 650 \mathrm{mg}$ $\mathrm{CO}_{2} / \mathrm{kg}$ per h) upon harvest and storage at $20 \mathrm{C}$ in the dark. The rate of $\mathrm{CO}_{2}$ production then declined during the next $24 \mathrm{~h}$ before stabilizing at $\approx 30 \%$ of the initial rate (Fig. $2 \mathrm{~A}$ ). The RQ declined in parallel with $\mathrm{CO}_{2}$ production (Fig. 2A), indicating an accompanying shift toward a more oxidative metabolism soon after harvest.

Ethylene production from branchlets increased markedly at $3 \mathrm{~h}$ before declining to near the initial rate by $24 \mathrm{~h}$ (Fig 2B). A similar transient increase in wound/stress ethylene production has been found in 'Green Beauty' and 'Dominator' broccoli after harvest, (King and Morris, 1994). Ethylene production varied little between 0.6 to $0.9 \mathrm{nl} \cdot \mathrm{g}^{-1} \cdot \mathrm{h}^{-1}$ during 24 to $96 \mathrm{~h}$.

Florets commenced yellowing between 48 and $72 \mathrm{~h}$ (Fig 2B), as indicated by decreasing hue angle, and yellowed markedly between 72 and $96 \mathrm{~h}$.

Fresh and dry weight distribution, and compositional data. Floral sections (mainly florets and pedicels) comprised $\approx 55 \%$ of the initial branchlet fresh weight and contained $13 \%$ dry matter. Middle and base sections each comprised $\approx 20 \%$ and $25 \%$ initial branchlet fresh weight and contained $11 \%$ and $8 \%$ dry matter, respectively. Florets are actively developing immediately before harvest and contain immature tissue, whereas base sections contain more mature tissue with an extensive pith area. The dry-weight distribution therefore reflects the relative developmental stages and cell sizes of the different sections of the broccoli branchlet.

Branchlets lost less than 5\% fresh weight over $96 \mathrm{~h}$ at $20 \mathrm{C}$, whereas their dry weight loss was $\approx 18 \%$. All compositional data are therefore expressed per unit fresh weight. 


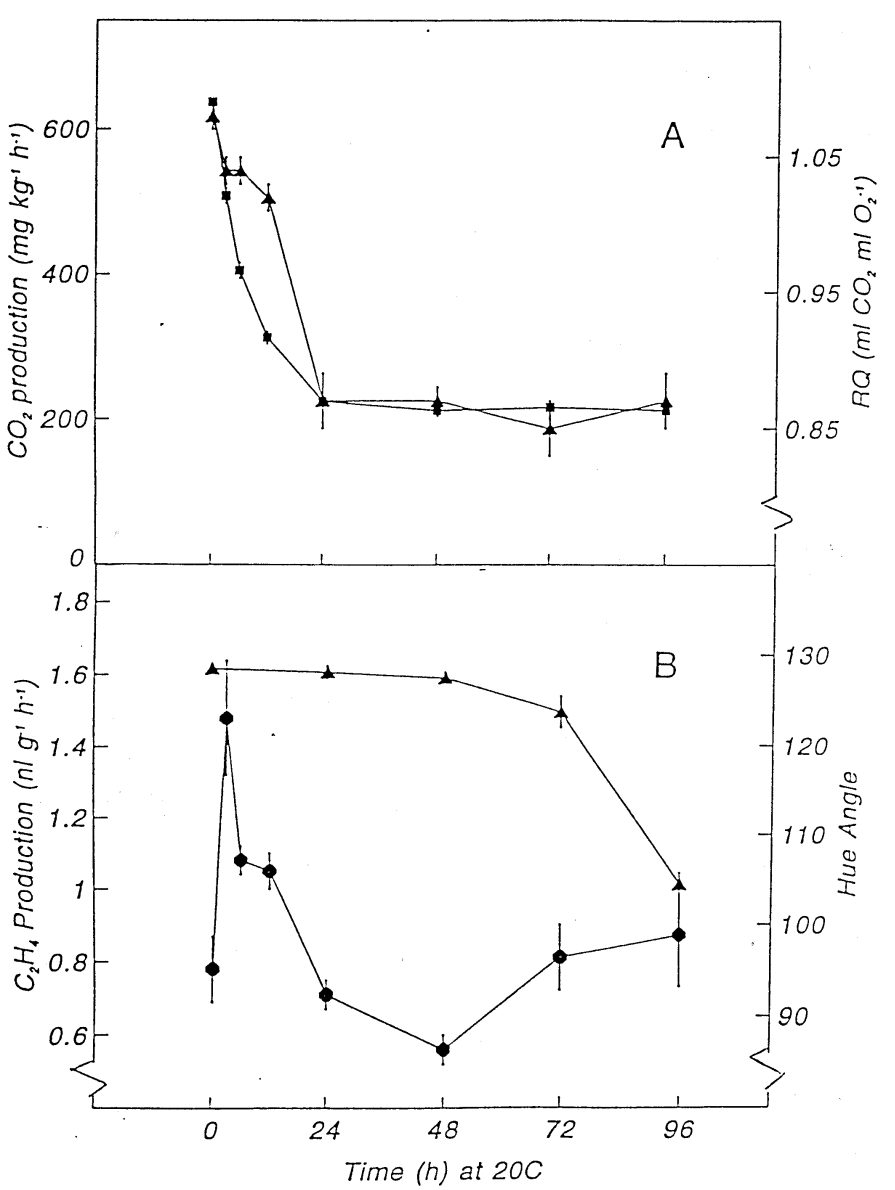

Fig. 2. Physiological changes in broccoli branchlets held at 20C in the dark. (A). $\mathrm{CO}_{2}$ production (square) and RQ (triangle). (B). Ethylene production (circle) and hue angle (triangle). Bars are SEs and are contained in the symbols when not shown.

Soluble sugars and starch. Glucose and fructose were the major soluble sugars in all sections of broccoli branchlets initially (Table 1). Sucrose was also present, but at much lower concentrations, and was largely depleted from all sections of branchlets by $24 \mathrm{~h}$ (data not presented). The soluble sugar concentration (sum of glucose, fructose, and sucrose) was $\approx 50 \%$ lower in floral sections than in middle and base sections (Table 1, Fig. 3A), both of which contained similar quantities of the individual sugars. The ratio of glucose to fructose did not alter markedly during postharvest senescence. The soluble sugar data presented from $24 \mathrm{~h}$ therefore largely reflects concurrent changes in these two sugars.

Soluble sugar content of floral and middle sections declined to an asymptotic level by $6 \mathrm{~h}$ (Fig. 3A). Base sections lost soluble sugars during the first $12 \mathrm{~h}$, however levels subsequently remained relatively unchanged (Fig. 3A). These results demonstrate little net loss of soluble sugars from sections of broccoli branchlets from 12 to $96 \mathrm{~h}$. Losses of sucrose accounted for $\approx 50 \%$ of the total sugar lost from floral and base sections during the first $12 \mathrm{~h}$, but only $\approx 30 \%$

Table 1. Major soluble sugars $\left(\mathrm{mg} \cdot \mathrm{g}^{-1}\right.$ fresh weight, SE in parentheses) present initially in different sections of broccoli branchlets.

\begin{tabular}{lrrr}
\hline \hline Section & Fructose & Glucose & Sucrose \\
\hline Floral & $4.5(0.35)$ & $6.9(0.49)$ & $1.2(0.64)$ \\
Middle & $13.3(0.35)$ & $14.5(0.67)$ & $3.8(2.40)$ \\
Base & $10.4(0.27)$ & $10.9(1.27)$ & $4.0(1.12)$ \\
\hline
\end{tabular}

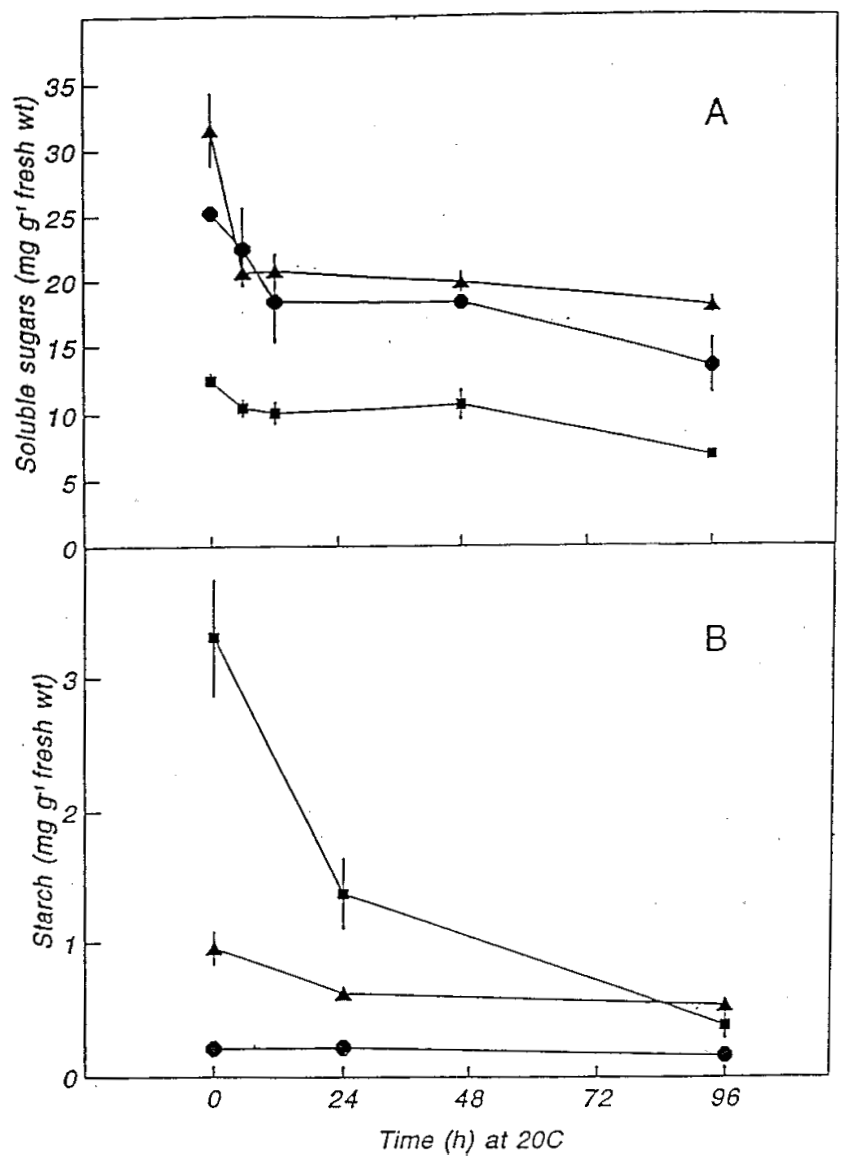

Fig. 3. Changes in soluble sugar (A) and starch (B) content of floral (square), middle (triangle), and base (circle) sections of broccoli branchlets held at 20C in the dark. Bars are SEs and are contained in the symbols when not shown.

of that lost from middle sections of branchlets (data not presented).

Starch was initially present in significant quantities only in floral and middle sections of branchlets (Fig. 3B). Starch content was highest in floral sections, and declined by $\approx 50 \%$ in both floral and middle sections during $24 \mathrm{~h}$ at $20 \mathrm{C}$. Starch was detected only at trace levels in all sections of broccoli branchlets by $96 \mathrm{~h}$. Iodine staining confirmed starch removal during the extraction procedure (data not presented).

Organic acids. Malic acid was the major organic acid present in all sections of broccoli branchlets initially, with citric acid being present at lower levels (Table 2). Both citric and malic acid concentrations changed similarly during postharvest senescence, so combined data for the two are presented (Fig. 4).

The organic acid content of middle and base sections of broccoli branchlets rose at $6 \mathrm{~h}$, and subsequently declined rapidly in all sections by $12 \mathrm{~h}$. Organic acid pools were totally depleted by $24 \mathrm{~h}$ in floral sections, $48 \mathrm{~h}$ in middle sections, and $72 \mathrm{~h}$ in base sections (Fig. 4).

Proteins, amino acids, and ammonia. The total protein content of floral sections declined moderately during the first $12 \mathrm{~h}$, and

Table 2. Major organic acids ( $\mathrm{mg} \cdot \mathrm{g}^{-1}$ fresh weight, SE in parentheses) present initially in different sections of broccoli branchlets.

\begin{tabular}{lcc}
\hline \hline Section & Malic acid & Citric acid \\
\hline Floral & $4.3(0.84)$ & $2.6(0.59)$ \\
Middle & $3.7(1.21)$ & $1.3(0.08)$ \\
Base & $2.6(0.44)$ & $0.8(0.13)$ \\
\hline
\end{tabular}




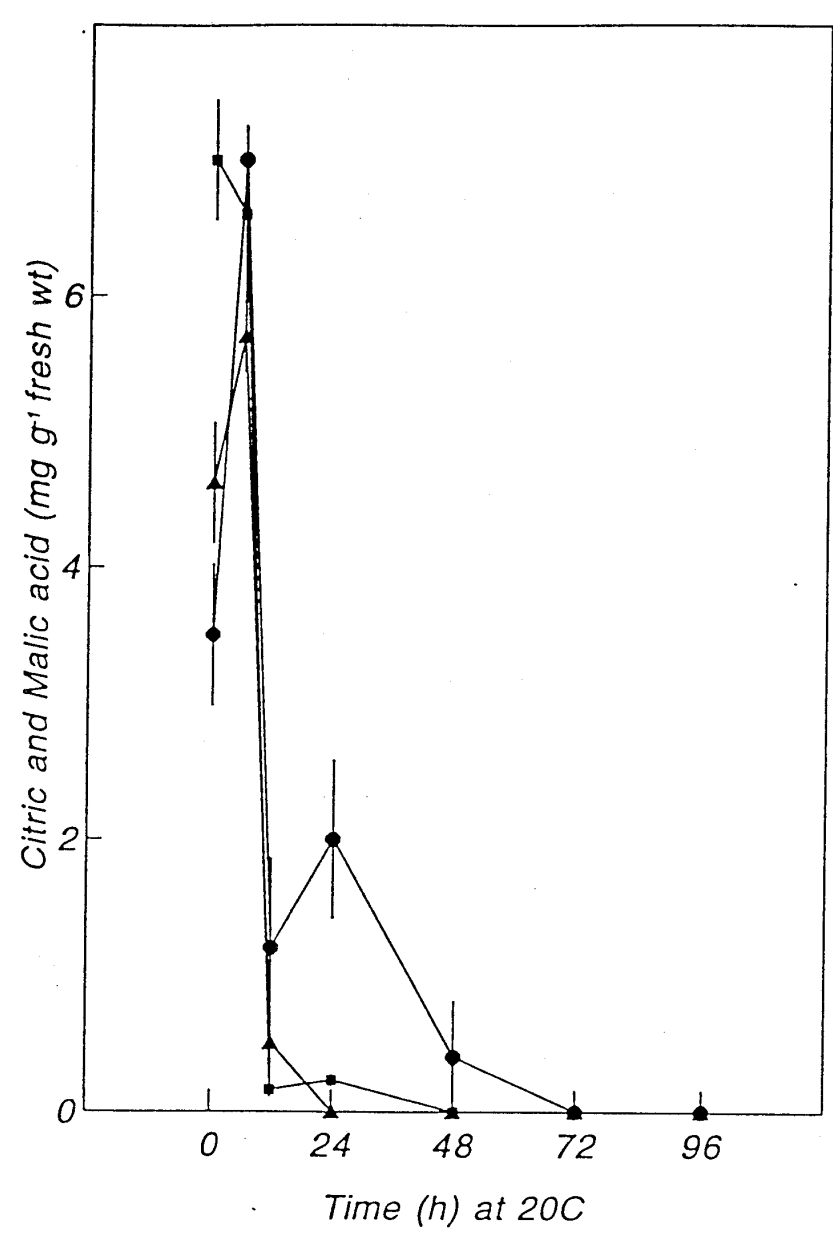

Fig. 4. Changes in organic acid content of floral (square), middle (triangle), and base (circle) sections of broccoli branchlets held at 20C in the dark. Bars are SEs and are contained in the symbols when not shown.

subsequently declined at a slower rate (Fig. 5A). The protein content of middle and base sections declined only slowly between 24 and $96 \mathrm{~h}$.

Amino acid changes in all sections of broccoli branchlets followed similar trends, so only data for floral sections are presented (Table 3). The free amino acid content of floral sections increased during $12 \mathrm{~h}$ at $20 \mathrm{C}$, with a doubling of the glutamine pool accounting for most of this increase (Table 3). By 96 h, most free amino acids had increased with asparagine, isoleucine, phenylalanine, and valine all showing greater than 5-fold increases from their initial levels. Deviating results were found only for alanine and glutamic acid (which accumulated to $\approx 2$-fold initial levels only in base sections at $96 \mathrm{~h}$ ), and arginine (which was depleted from base sections by $96 \mathrm{~h}$; data not shown).

The ammonia content of floral sections increased between 24 and $72 \mathrm{~h}$, and increased further again at $96 \mathrm{~h}$ (Fig. 5B). The ammonia content of middle and base sections remained unchanged during senescence.

\section{Discussion}

Harvesting and handling broccoli for market imposes a series of stresses on tissue, including wounding, separation from nutrient source, and dehydration. Harvest stresses are particularly severe on organs containing immature tissue that was actively growing at harvest (e.g., broccoli florets). These organs are unable to maintain metabolic homeostasis and senesce rapidly (Huber, 1987).
Table 3. Changes in free amino acid content $\left(\mathrm{mg} \cdot \mathrm{g}^{-1}\right.$ fresh weight, SE in parentheses) in floral sections of broccoli branchlets held at $20 \mathrm{C}$ for up to $96 \mathrm{~h}^{\mathrm{z}}$.

\begin{tabular}{lccc}
\hline \hline & \multicolumn{3}{c}{ Time $(\mathrm{h})$ at $20 \mathrm{C}$} \\
\cline { 2 - 4 } Amino acid & 0 & 12 & 96 \\
\hline Alanine & $0.1(0.03)$ & $0.1(0.03)$ & $0.1(0.03)$ \\
Arginine & $0.2(0.03)$ & $0.1(0.01)$ & $0.5(0.03)$ \\
Asparagine & $0.1(0.05)$ & $0.2(0.04)$ & $1.1(0.03)$ \\
Aspartic acid & $0.2(0.01)$ & $0.2(0.02)$ & $0.3(0.01)$ \\
Glutamine & $0.7(0.07)$ & $1.4(0.06)$ & $1.9(0.10)$ \\
Glutamic acid & $0.5(0.09)$ & $0.6(0.03)$ & $0.4(0.01)$ \\
Histidine & $0.1(0.04)$ & $0.1(0.02)$ & $0.3(0.01)$ \\
Isoleucine & Trace & $0.1(0.01)$ & $0.2(0.01)$ \\
Leucine & Trace & $0.1(0.01)$ & $0.1(0.01)$ \\
Lysine & Trace & Trace & $0.1(0.01)$ \\
Methionine & Trace & Trace & Trace \\
Phenylalanine & Trace & $0.1(0.01)$ & $0.4(0.01)$ \\
Proline & $0.1(0.01)$ & $0.1(0.01)$ & $0.1(0.01)$ \\
Serine & $0.2(0.02)$ & $0.2(0.01)$ & $0.5(0.01)$ \\
Threonine & $0.1(0.01)$ & $0.1(0.02)$ & $0.1(0.01)$ \\
Tyrosine & Trace & Trace & $0.1(0.01)$ \\
Valine & $0.1(0.01)$ & $0.1(0.01)$ & $0.5(0.02)$ \\
Total & $2.5(0.26)$ & $3.5(0.11)$ & $6.6(0.02)$ \\
\end{tabular}

${ }^{\mathrm{z}}$ Trace is $<0.03 \mathrm{mg} \cdot \mathrm{g}^{-1}$ fresh weight.

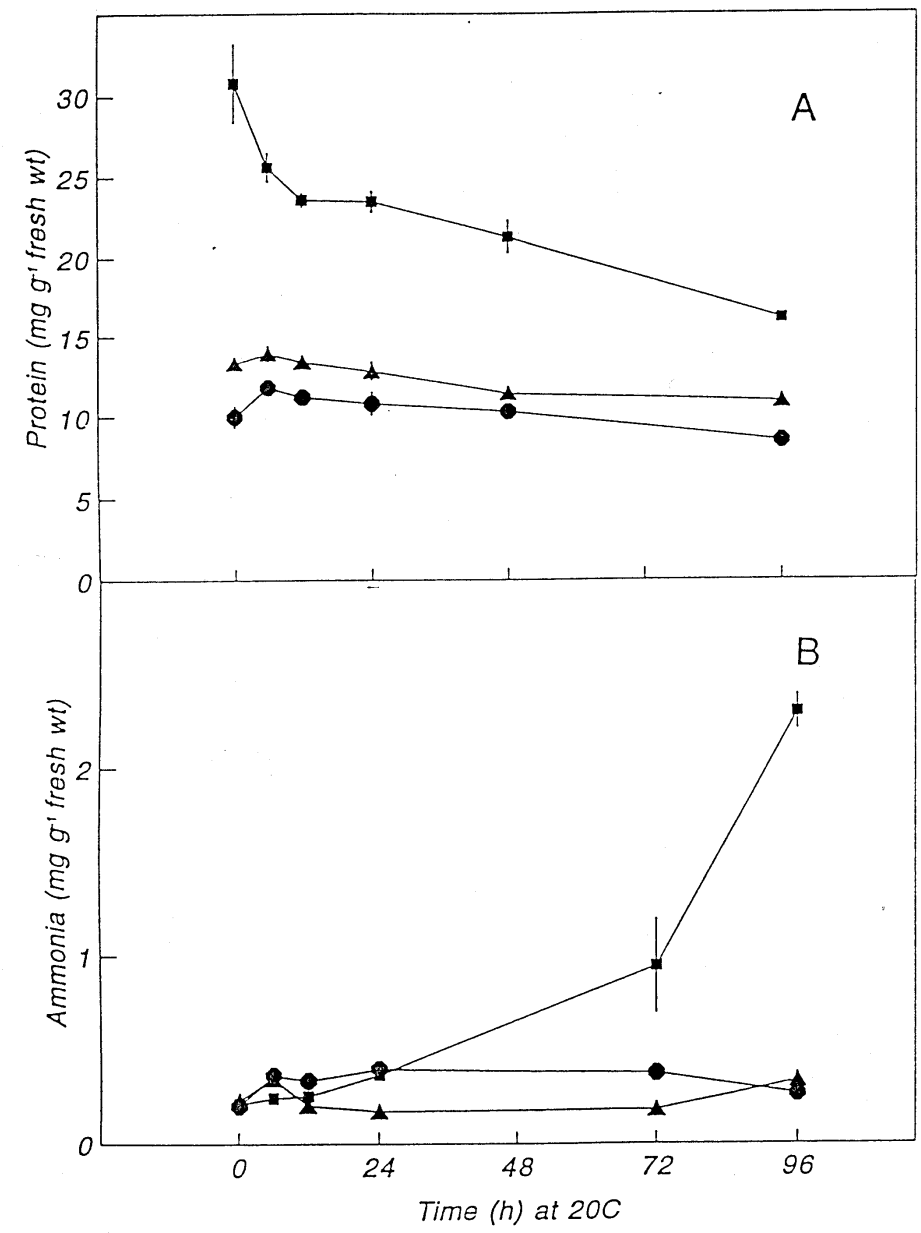

Fig. 5. Changes in total protein (A) and ammonia (B) content of floral (square), middle (triangle), and base (circle) sections of broccoli branchlets held at 20C in the dark. Bars are SEs and are contained in the symbols when not shown. 
Carbon dioxide production and RQ of 'Green Belt' broccoli branchlets declined rapidly during $12 \mathrm{~h}$ at 20C. Similar early changes in respiratory metabolism have been found in other broccoli cultivars, and may trigger or reflect the onset of postharvest senescence (King and Morris, 1994).

A decline in $\mathrm{CO}_{2}$ production and $\mathrm{RQ}$ was accompanied by losses of metabolites from broccoli branchlets. When the losses of starch, sugars, organic acids, and protein are considered against the respiration requirements (calculated as hexose units) of branchlets over $48 \mathrm{~h}$, there was a greater loss of metabolites than required to account for $\mathrm{CO}_{2}$ production (theoretical dry weight loss $=10 \%$, reconstructed branchlet metabolite loss $=17 \%$; calculations not presented), especially during the first $12 \mathrm{~h}$ (theoretical dry weight loss $=4 \%$, reconstructed branchlet metabolite loss $=12 \%$; calculations not presented). This suggests some use of metabolites for other purposes (e.g., growth or maturation-related processes).

Losses of sugars were greatest in middle and base sections during the first $12 \mathrm{~h}$, and greatly exceeded that required to support $\mathrm{CO}_{2}$ production from these sections (data not presented). In addition to biosynthetic processes, it is likely that some of these sugars were translocated to floral sections to help maintain the floral sugar pool and support the high respiratory demand of floral sections (King and Morris, 1994). Conversion of starch to glucose and fructose in floral sections during the first $24 \mathrm{~h}$ would also contribute to maintaining the floral sugar pools.

The rapid decline in organic acids from all sections of 'Green Belt' broccoli branchlets at 6 to $12 \mathrm{~h}$ strongly suggests that these components were oxidized at this time. This does not always occur in other broccoli cultivars (Dostal et al., 1965). Increased levels of organic acids in middle and base sections at $6 \mathrm{~h}$ may reflect activation or derepression of phosphoenylpyruvate carboxylase activity to replenish citric acid cycle intermediates as occurs in other stress situations (Tietz and Wild, 1991). Theoretical calculations of RQs for the oxidation of organic acids commonly give ratios around 1.3, the exact value depending on the organic acid being oxidized. As the RQ consistently declined during the first 12 h, sugars, organic acids, and other cellular components were all probably being oxidized by branchlets during this period, with the RQ reflecting a composite value. The rapid loss of protein from floral sections during the first $12 \mathrm{~h}$ supports this view. Although no determination of lipid has yet been undertaken, any lipid oxidized would contribute to the low RQ detected.

Use of protein as respiratory substrate when sugars are still present in tissue has been observed. Platenius (1942) provided evidence that proteins were oxidized in addition to sugars during the postharvest senescence of asparagus. Further, Yemm (1937) showed that protein of detached barley leaves held in the dark was used for respiration during the first $12 \mathrm{~h}$ when sugars were still present. Some of the sugar pools may be contained in compartments inaccessible to respiratory processes (Saglio and Pradet, 1980). In this case, very rapid depletion of the accessible sugar pools will place tissue under carbohydrate stress. Maintenance of the sugar pools in all sections of broccoli branchlets accompanied by both a low RQ during 12 to $96 \mathrm{~h}$ and a total branchlet energy deficit at $96 \mathrm{~h}$ (theoretical dry weight loss $=20 \%$, reconstructed branchlet metabolite loss $=17 \%$; calculations not presented), indicates the use of alternative respiratory substrate(s) during the later stages of postharvest senescence.

Changes in the metabolism of nitrogen-containing compounds in addition to protein were also detected in senescing broccoli branchlets. Glutamine and asparagine accumulated to high levels by $96 \mathrm{~h}$, with the two amides collectively accounting for $\approx 50 \%$ of the free amino acids present during late senescence. Amide accu- mulation, together with maintenance of the glutamic acid pool, strongly suggests operation of the glutamine synthetase/asparagine synthetase pathway reassimilating ammonia produced by proteolysis in floral sections to fuel respiration under starvation stress conditions (Genix et al., 1990; Hurst et al., 1993a; Peoples and Dalling, 1988; Sieciechowicz et al., 1988).

Accumulation of amides in middle and base sections seems unusual, as large net protein loss occurred only in floral sections. Amides are commonly synthesized as $\mathrm{N}$ transport compounds (Rabe, 1990), and their distribution may reflect translocation from the floral tissues to other sections of the branchlet after harvest.

Isoleucine, valine, and phenylalanine accumulated to greater than 5-fold their initial levels by $96 \mathrm{~h}$. Both isoleucine and valine are considered major amino acids of membrane proteins, which are a source of oxidizable substrate for ATP production via $\beta$-oxidation of their 2-oxo acids (Genix et al., 1990). Isoleucine and valine presumably accumulate because their rate of production exceeds their rate of use by the cells. Breakdown of chloroplast membranes (occurring from $48 \mathrm{~h}$ in broccoli florets, M. Vesk, personal communication) is a potential source of both protein and lipid which may be recycled during senescence to provide respiratory substrate. Phenylalanine accumulation is commonly observed in plant tissues placed in starvation conditions (Brouquisse et al., 1992; King et al., 1990). This suggests that phenylalanine is only partially recycled or degraded in these situations.

Ammonia accumulated only in floral sections of branchlets during late senescence. Floral sections have a 4-fold higher respiration rate compared with other sections of broccoli branchlets (King and Morris, 1994). Ammonia probably accumulates because of depletion of available carbon skeletons required for its assimilation (Hurst et al., 1993a).

Yellowing of florets 3 to 4 days after harvest is the most striking symptom of the postharvest senescence of broccoli, and can be regulated by ethylene (Aharoni et al., 1985; Tian et al., 1994; Wang, 1977). The onset of yellowing of 'Green Belt' florets was not correlated with major changes in endogenous ethylene production by entire branchlets during senescence at 20C. Similar results have been found with 'Shogun', 'Dominator', and 'Green Beauty' broccoli branchlets (King and Morris, 1994). However, branchlets contain much vegetative tissue, which may mask significant changes in ethylene production by the reproductive structures of the broccoli florets (Tian et al., 1994). Further, the sensitivity of florets to exogenous propylene increases $24 \mathrm{~h}$ after harvest (Tian et al., 1994), and may also influence yellowing.

Yellowing of florets is clearly a relatively late event in the postharvest senescence of broccoli, preceded by major physiological and compositional changes from very early after harvest. The changes in respiration, carbon metabolism, and nitrogen metabolism are consistent with changes described for plants in stress situations. The relationship between these early metabolic changes and increased sensitivity of florets to ethylene and/or changes in ethylene production in floral tissue merits further research.

\section{Literature Cited}

Aharoni, N., S. Philosoph-Hadas, and R. Barkai-Golan. 1985. Modified atmospheres to delay senescence and decay of broccoli. Proc. 4th Natl. Atmosphere Conference, Dept. Hort. Sci., Raleigh, N.C. Hort. Rpt. 126:169-177.

Brouquisse, R., F. James, A. Pradet, and P. Raymond. 1992. Asparagine metabolism and nitrogen distribution during protein degradation in sugar-starved maize roots. Planta 188:384-395.

Davies, K.M. and G.A. King. 1993. Isolation and characterization of a cDNA clone for a harvest-induced asparagine synthetase from Aspara- 
gus officinalis L. Plant Physiol. 102:1337-1340.

Dostal, H.C., R.R. Dedolph, and V. Tuli. 1965. Changes in the nonvolatile organic acid constituents in broccoli (Brassica oleracea var. italica) following postharvest $\mathrm{N}^{6}$-benzyladenine treatment. Proc. Amer. Soc. Hort. Sci. 86:387-391.

Genix, P., R. Bligny, J-B. Martin, and R. Douce. 1990. Transient accumulation of asparagine in sycamore cells after a long period of sucrose starvation. Plant Physiol. 94:717-722.

Huber, D.J. 1987. Postharvest senescence: an introduction to the symposium. HortScience 22:853-854.

Hurst, P.L., G.A. King, and W.M. Borst. 1993a. Postharvest inhibition of glutamine synthetase activity with phosphinothricin reduces the shelflife of asparagus. Postharvest Biol. Technol. 3:327-334.

Hurst, P.L., G.A. King, D.C. Woollard, and W.M. Borst. 1993b. Nitrogen metabolism in harvested asparagus: no difference between light and dark storage at 20C. Food Chem. 47:329-332.

King, G.A. and S.C. Morris. 1994. Physiological changes of broccoli during early postharvest senescence and through the preharvest/ postharvest continuum. J. Amer. Soc. Hort. Sci. 119:270-275.

King, G.A., D.C. Woollard, D.E. Irving, and W.M. Borst. 1990. Physiological changes in asparagus spear tips after harvest. Physiol. Plant. 80:393-400.

Lill, R.E., G.A. King, and E.M. O’Donoghue. 1990. Physiological changes in asparagus spears immediately after harvest. Scientia Hort. 44:191199.

Lowry, O.H., N.J. Rosebrough, A.L. Farr, and R.J. Randall. 1951. Protein measurement with the Folin phenol reagent. J. Biol. Chem. 193:265275.

Makhlouf, J., C. Willemot, J. Arul, F. Castaigne, and J-P. Emond. 1989. Long-term storage of broccoli under controlled atmosphere. HortScience 24:637-639.

O'Brien, T.P. and M.E. McCully. 1981. The study of plant structure: Principles and selected methods. Termarcarphi Party Ltd., Melbourne. p. 6.95-6.96.

Peoples, M.B. and M.J. Dalling. 1988. The interplay between proteolysis and amino acid metabolism during senescence and nitrogen reallocation, p. 182-217. In: L.D. Nooden and A.C. Leopold (eds.). Senescence and aging in plants. Academic Press, San Diego.

Platenius, H. 1942. Effect of temperature on the respiration rate and the respiratory quotient of some vegetables. Plant Physiol. 17:179-187.

Rabe, E. 1990. Stress physiology: the functional significance of the accumulation of nitrogen-containing compounds. J. Hort. Sci. 65:231243.

Rushing, J.W. 1990. Cytokinins affect respiration, ethylene production, and chlorophyll retention of packaged broccoli florets. HortScience 25:88-90.

Saglio, P.H. and A. Pradet. 1980. Soluble sugars, respiration, and energy charge during aging of excised maize root tips. Plant Physiol. 66:516519.

Sieciechowicz, K.A., K.W. Joy, and R.J. Ireland. 1988. The metabolism of asparagine in plants. Phytochemistry 27:663-671.

Smith, W.H. 1940. The storage of broccoli and cauliflower. J. Pomol. Hort. Sci. 18:287-293.

Tian, M.S., C.G. Downs, R.E. Lill, and G.A. King. 1994. A role for ethylene in the yellowing of broccoli. J. Amer. Soc. Hort. Sci. 119:276281.

Tietz, S. and A. Wild. 1991. Investigations on the phosphoenolpyruvate carboxylase activity of spruce needles relative to the occurrence of novel forest decline. J. Plant Physiol. 137:327-331.

Wade, N.L. and S.C. Morris. 1982. Rapid determination of sugars in cantaloupe melon juice by high-performance liquid chromatography. $\mathrm{J}$. Chromatography 240:257-261.

Wang, C.Y. 1977. Effect of aminoethoxy analog of rhizobitoxine and sodium benzoate on senescence of broccoli. HortScience 12:54-56.

Yemm, E.W. 1937. Respiration of barley plants. III. Protein metabolism in starving leaves. Proc. Royal Soc. London. 123:243-273. 